\title{
BITTERSWEET FOOD
}

\author{
SHEN-YI LIAO \\ University of Puget Sound \\ sliao@pugetsound.edu
}

SUMMARY: Nostalgia and food are intertwined universals in human experience. All of us have experienced nostalgia centered on food, and all of us have experienced food infused with nostalgia. To explore the links between nostalgia and food, I start with a rough taxonomy of nostalgic foods, and illustrate it with examples. I argue that there is a psychological commonality to experiencing nostalgic foods: imagination. On my account, imagination is the key to understanding the cognitive, conative, affective, and perceptual aspects of experiencing nostalgic foods. In turn, the recognition of imagination's centrality in experiencing nostalgic foods reveals how food can produce aesthetic experiences comparable to those produced by literature and painting.

KEY WORDS: imagination, nostalgia, memory, aesthetic experience, nostalgic food

RESUMEN: La nostalgia y la comida son universales interconectados en la experiencia humana. Todos hemos tenido experiencias nostálgicas con la comida y hemos experimentado una comida impregnada de nostalgia. Para explorar las conexiones entre ambas, presento una taxonomía de la comida nostálgica con ejemplos. Argumento que existe algo común en la experiencia de la comida nostálgica: la imaginación. Propongo que la imaginación es fundamental para entender los aspectos cognitivos, conativos, afectivos y perceptuales de la experiencia de comida nostálgica. Además, la importancia de la imaginación en la experiencia de la comida nostálgica revela cómo la comida puede producir experiencias estéticas comparables a aquellas producidas por la literatura o la pintura.

PALABRAS CLAVE: imaginación, nostalgia, recuerdos, experiencia estética, comida nostálgica

\section{What is a food that makes you nostalgic?}

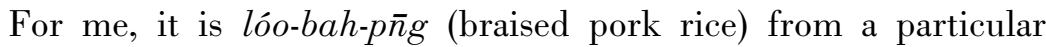
eatery near my home in Taiwan. When I was in elementary school, my parents were both working and busy. So while many other kids had homemade leftovers for lunch, mine would often be this particular eatery's lóo-bah-png. . It became the center of my nostalgia for that period, for my childhood, for a place that I still consider my home. In turn, my present-day aesthetic experiences of eating the lóo-bah-p $\bar{n} g$ from the same eatery are inevitably infused with nostalgia. In fact, every time I return to Taiwan I still go back to the same eatery in an unquestionably quixotic attempt to again experience that ló-bah- 
$p \bar{n} g$ that exists in my mind, even though the ones that I experience in the present somehow never smell or taste quite the same.

Despite person-to-person variations in the details, I think the core of my aesthetic experience with nostalgic food is likely to resonate with other people. In nearly every language, there is a word that corresponds to the English "nostalgia" that tracks the idea of a backward-looking longing (Gotlib 2018). And, across different contexts, food persists as a central force in the formation of cultural —as well as personal-identities. It is no surprise that nostalgia and food are intertwined universals in human experience (Gotlib 2018; Locher et al. 2015). All of us have experienced nostalgia centered on food, and all of us have experienced food infused with nostalgia.

To explore the links between nostalgia and food, I start with a rough taxonomy of nostalgic foods, and illustrate it with examples (section 1). Drawing on contemporary cognitive science of nostalgia, I argue that there is a psychological commonality to experiencing nostalgic foods of all kinds: imagination (section 2). On my account, imagination is the key to understanding the cognitive, conative, affective, and perceptual aspects of experiencing nostalgic foods (section 3). In turn, the recognition of imagination's centrality in experiencing nostalgic foods reveals how food can produce aesthetic experiences comparable to those produced by literature and painting (section 4).

\section{Varieties of Nostalgic Foods}

In the academic study of nostalgia, there is a common distinction between "personal" versus "historical" varieties (Havlena and Holak 1991; Holak and Havelena 1992; Stern 1992). For example, Barbara J. Stern characterizes personal nostalgia as being about "the way $I$ was" and historical nostalgia as being about "the way it was" (1992, pp. 13-16). We can use this distinction to start to build a rough taxonomy of nostalgic foods (subsection 1.1 and subsection 1.2), before considering the similarities and differences between different types of nostalgic foods (subsection 1.3).

\subsection{Personally-Nostalgic Foods}

Personally-nostalgic foods are the ones that came to mind when I asked "what is a food that makes you nostalgic?". Following Stern's distinction, these are foods that correspond to the way you were. Since each personally-nostalgic food is born from each individual's 
personally-important experience, there is predictably much interpersonal variance when it comes to personally-nostalgic foods. I am personally nostalgic for lóo-bah-p $\bar{n} g$, but you are probably not.

A particularly interesting example of personally-nostalgic food comes from performance artist Marina Abramović, in the form of a macaron that "tastes of her". ${ }^{1}$ As Abramovic describes the flavors in a press release:

My grandmother, early morning, making coffee. She never trusted anybody to buy ready coffee, she would buy the green beans and then burn them herself, the smell of coffee was everywhere in the house. Then I remember the smells of fresh basil, thyme, cardamom seeds, and exotic smells from the trips I took later on and remember exploring volcanoes and waterfalls and remember this feeling in the early morning when I see the line of the sea just meet the ocean, and ocean meet the sky. All of this, in this macaron of me. (Rea 2017)

Despite Abramović's commercialization of her macaron, it remains distinctively a personally-nostalgic food. While the combination of smells and tastes presumably evokes nostalgia for Abramovic herself, due to her association of them with personally-important experiences, they presumably cannot evoke nostalgia for anyone else. Indeed, her macaron only promises consumers a taste of Marina Abramovic, not a taste of their own childhoods.

\subsection{Historically-Nostalgic Foods}

Historically-nostalgic foods, by contrast, have the social function of evoking nostalgia. Following Stern's distinction, these are foods that relate to the way it was - where that "it" can be a historical period, a cultural background, or even a developmental stage that is shared and significant. For example, in Taiwan it is common to find food marketed as kóo-tsá-b $\bar{\imath}$ (traditional-tasting, or literally "taste of old"). Typically, a kóo-tsá-bi food is representative of an important intersection between culture and history. For example, despite the use of a New World crop, han-tsî-muê (sweet potato congee) has become interwoven into Taiwanese identity via a culinary tradition that is thought to be distinctively Taiwanese, and an association with the harsh material conditions of pre-economic-development eras in Taiwan's history (Chang 2013). It is this connection to identity

${ }^{1}$ Compare Korsmeyer 2019. 
construction that allows historically-nostalgic foods to evoke nostalgia as their social function. ${ }^{2}$

Given the variety of things that can be "it" in "the way it was", however, the category of historically-nostalgic foods can be further divided into two sub-categories: intentionally-designed versus culturally-emergent.

A particularly interesting example of intentionally-designed historically-nostalgic food comes from the Chicago modernist restaurant Next, in the form of its Childhood tasting menu, which ran from October 2011 to January 2012. Phil Vettel offers one particular interpretation of, and a way to appreciate, the opening course in his review in Chicago Tribune:

As the meal begins, you're confronted by three cocktail glasses, containing an olive, cherry and bit of celery, respectively, along with a corresponding tablespoon's worth of Martini, Manhattan and Bloody Mary. I actually waited for the glasses to be filled before a waiter informed me that presentation was complete, and then I caught on - the presentation mimicked the sip-of-dad's-cocktail experience. Ideally, one would accompany each sip with a furtive, over-the-shoulder glance. (2011)

As the name of the tasting menu indicates, this course is intentionally designed to evoke childhood nostalgia. However, the success of the three-cocktails course lies in its ability to evoke nostalgia for a wide variety of consumers coming from different times and places. Even though this course is like personally-nostalgic foods insofar as it is associated with personally-important experiences, it is also unlike personally-nostalgic foods insofar as it is not specific to any individual. Instead, if Vettel's response is indicative, the three-cocktails course is aesthetically impressive because it is able to evoke a kind of nostalgia that is about, and associated with, a common developmental stage. We can readily recognize the infusion of nostalgia in this course by considering a counterfactual: if nostalgia were not a central component of the aesthetic experience of this course, then it would be no more than three stingy servings of familiar cocktails, which would be rather aesthetically unimpressive.

However, not all historically-nostalgic foods are creations of gastronomy geniuses or marketing machines. Quite often, as is the case

${ }^{2}$ Indeed, national identity and culinary culture are generally socially coconstructed. To elucidate this general process through a specific example, Sarah Bak-Geller Corona $(2016,2019)$ analyzes the co-construction of Mexican national identity and Mexican culinary culture. 
with kóo-tsá-bi foods of Taiwan, they are about, and associated with, particular eras of particular cultures. While these foods can in principle be consumed and enjoyed by themselves, nostalgia does seem central to the aesthetic experiences that they afford, even for presentday consumers who have not personally experienced the historical and cultural background referenced. For example, while consumers might not eat dried sweet potatoes otherwise, they might eat it as a part of han-tsî-muê because it is infused with historical nostalgia.

A particularly interesting example of culturally-emergent historically-nostalgic food comes from the use of canned red tomatoes, as opposed to the traditional pickled green tomatoes, in Georgian cuisine after the dissolution of the Soviet Union (Dunn 2008). During the fourth and fifth Five Year Plans, the Soviet Union invested heavily in industrial canned food production in Georgia, and in turn canned fruits and vegetables became central to Georgian cuisine. So when industrial canned foods became unavailable after the dissolution of the Soviet Union, many Georgians turned to home-canned fruits and tomatoes in their search for these historically-nostalgic foods, which resulted in hyperendemic botulism across the country. As Elizabeth Cullen Dunn argues in her anthropological case study:

[...] botulism is, first of all, the product of a locally specific nostalgia, dietary desires evoked by a state that no longer exists. People who want canned red tomatoes are harkening back to the taste of the Soviet empire, to a world in which an industrial state provided food to its citizen-consumers as a way of linking them to the body politic. The yearning for red tomatoes thus is not just a longing for vegetables, no matter how tasty, but a culturally and historically specific longing for a lifeworld that was predictable (even if it was predictably awful), a state whose existence one could perceive in the material objects of daily life, and a regulatory environment that provided a measure of physical safety and existential security that no longer obtains (2008, p. 254).

The use of canned red tomatoes clearly has the social function of evoking nostalgia for a wide variety of individuals. On Dunn's analysis, post-Soviet Georgians' nostalgia for canned red tomatoes includes representationally-rich associations of canned red tomatoes with a predictable and predictably awful Soviet state, complicated and nuanced emotional responses, and a desire that is so great that they literally risk dying for it. 


\subsection{Differences and Similarities}

The foregoing taxonomy is useful because it shows us a variety of nostalgic foods, with some (hopefully) memorable exemplars. However, it is only one way to recognize the diversity of nostalgic foods. For one, the categories are not mutually exclusive: for example, there are historically-nostalgic foods that are also some people's personallynostalgic foods. For another, there exist other notable dimensions of variation. First, nostalgic foods only partially overlap with comfort foods: some comfort foods are not nostalgic foods, such as indulgence foods and convenience foods (Locher et al. 2005); and some nostalgic foods are not comfort foods, such as Abramović's macarons. Second, some nostalgic foods are essentially intertwined with culturally and historically bound notions of culinary authenticity (Strohl 2019), ${ }^{3}$ such as Taiwanese han-tsî-muê and Georgian canned red tomatoes, but others stand independently of such notions, such as Next's three-cocktails course.

Nevertheless, I contend that there is something significant that is common to experiencing nostalgic foods of all kinds. We have to acknowledge the messiness of social reality to avoid reductive explanations, but we also have to not lose sight of the meaningful universality of experiencing nostalgic foods. Despite the variations, there exist psychological commonalities to experiencing nostalgic foods, whether it is my experiencing a personally-nostalgic lóo-bah-p $\bar{n} g$, my experiencing a historically-nostalgic han-tsî-muê, or my experiencing Next's historically-nostalgic three cocktails.

There are multiple aspects to the psychological profile of experiencing nostalgic foods. Cognitively, it involves representations of a subjective past, which may be more or less idealized, or even fictional. As Stern puts it, "Just as historical nostalgia idealizes the imaginatively recreated past, so too does personal nostalgia idealize the personally remembered past" (1992, p. 16). Conatively, it involves a backward-looking longing. Affectively, it involves a bittersweet feeling that mixes a positive valence toward the subjective past and a negative valence toward the incongruence between the past and the present. Perceptually, it involves smells and tastes that are modified or modulated by the aforementioned cognitive, conative, and affective states. To better understand each of these aspects, we now turn to the cognitive science of nostalgia in general.

\footnotetext{
${ }^{3}$ See also papers collected in Korsmeyer 2016, Part VIII.
} 


\section{Cognitive Science of Nostalgia}

Traditionally, nostalgia was pathologized and medicalized as a mental illness, rather than being recognized as just another aspect of our complex mental lives. On the traditional conception of nostalgia, the cognitive component consists of the retrieval of autobiographical memories of one's home; the affective component consists of only negatively-valenced emotions; and the conative component consists of a desire to return to one's homeland. Against this traditional conception, Felipe De Brigard synthesizes recent empirical research on memory to propose a modern conception of nostalgia.

It is central to De Brigard's modern conception that the cognitive component of nostalgia consists of a wide variety of types of mental simulation. While retrieval of autobiographical memory of one's home is one kind of mental simulation, there are many other kinds that can take its place in nostalgic episodes. First, even when nostalgia includes autobiographical memories, they need not be about one's home; instead, they can be about one's childhood, family, or even something as general as "the way people were" (Batcho 2013; cited in De Brigard 2018, p. 159). Second, even when nostalgia includes memories of the past, the memories need not be episodic - that is, they need not be about specific events; instead, they can be about social relationships or one's childhood (Hepper et al. 2012, 2014; cited in De Brigard 2018, p. 159). Third, nostalgia can include mental simulations that are about a past that one never personally experienced; for example, a teenager today who is very into post-punk might feel intensely nostalgic about the 1980s scene (De Brigard 2018, pp. 160161). In fact, the mental simulations can also be about a possible past, a possible present, or even a possible future (De Brigard 2018, p. 162). To sum up, on the modern conception, while the cognitive component of nostalgia can be constituted by memory in a narrow autobiographical sense, it can also be constituted by other types of mental simulation.

This expanded conception of the cognitive component of nostalgia fits with, and indeed arises from, an expanded conception of memory that has emerged from recent cognitive science. The traditional preservationist conception of memory is that it operates like an archive: information is simply encoded, stored, preserved, and retrieved. However, recent cognitive science has challenged this traditional conception in favor of a constructivist conception of memory, on which remembering is "an active process in which the subject constructs a more or less adequate representation of the past" 
(Michaelian and Sutton 2017). The constructivist conception of memory is more expansive insofar as it weakens or omits requirements on veracity and causal connection. That is, depending on the specific theory, remembering may not require the subject to represent perfectly accurately in all respects, and remembering may not require an appropriate causal connection between the subject's representation and their original experience.

On the constructivist conception of memory, there is a psychological continuity between remembering and imagining (De Brigard 2014; Hopkins 2018; Michaelian 2016, 2018; Shanton and Goldman 2010; but see also Debus 2014, 2016, 2018 and Robins 2020; see Liao and Gendler 2019, sec. 2.4, for an overview). Of course, the subject may still metacognitively label some outputs as "memories" and others as "imaginings", but the crucial claim is that the outputs are generated by the same set of psychological processes (Michaelian 2016; Debus 2018). Different theorists give different labels to this set of psychological processes: "mental time travel" (Michaelian 2016; Schachter, Addis, and Buckner 2007), "mental simulation" (De Brigard 2014, 2018), or simply "imagination" (Michaelian 2018). I am most sympathetic to that last label, according to which "the common overarching capacity is imagination [...] divide into episodic and semantic types" (Michaelian 2018, p. 102). That is, the mental states that we typically label as "memories" are imaginings of a specific sort: past-directed imaginings. Specifically, the phrase "past-directed" is intended to encode the subjective temporal dimension of memories - that they present to the subject as looking back to the past - but without a commitment to the now-controversial veracity or causal connection requirements. From this more general account of memory as past-directed imaginings, we can tweak De Brigard's account and say that the cognitive component of nostalgia is constituted by imaginings, especially pastdirected imaginings.

De Brigard's modern conception of nostalgia also reconceptualizes the affective and conative components. The affective component, as recent social psychological research has shown, consists of both positively- and negatively-valenced emotions (De Brigard 2018, pp. 163-165; see also Hepper et al. 2012 and Sedikides and Wildschut 2016). Specifically, this mixed-valenced affective response comes from the fact that nostalgic episodes are at once about the past and the present. So they characteristically include a positivelyvalenced emotion evoked by past-directed imaginings but also a negatively-valenced emotion evoked by the incongruence between 
the context of the imagined past and the context of the experienced present. In turn, the conative component of nostalgia consists of a desire to resolve this incongruence (De Brigard 2018, pp. 169-170; compare Gotlib 2018). For example, the desire might involve a motivation to make the present like the (imagined) past, so that the positively-valenced emotion evoked by past-directed imaginings can be made real.

\section{Experiencing Nostalgic Foods}

The cognitive science of nostalgia points to an imaginative account of experiencing nostalgic foods. To fill out this imaginative account, I will turn to Kendall Walton's influential account of the role of imagination in games of make-believe (subsection 3.1). My proposal, in brief, is that nostalgic foods are props for our games of makebelieve. Some of these, such as our peculiar esoteric nostalgic foods, only prompt us to games of our own. But others, such as those that have the social function of evoking nostalgia, prompt us to games that we share with people of a similar culture, a similar history, or a similar age group. Then, I will return to Felipe de Brigard's account of nostalgia to elucidate the cognitive (subsection 3.2), as well as the affective and conative (subsection 3.3) aspects of experiencing nostalgic foods. Finally, I will explain the role of imagination in the perceptual aspect of experiencing nostalgic foods (subsection 3.4).

\subsection{Walton on Make-Believe}

One of Walton's key insights is that there is a continuity between children's games of make-believe and representational arts like literature and painting - namely, their use of props (1990, pp. 35-43). When a child takes a toy phone and pretends to make a call, the toy phone functions as a prop for the child's make-believe: it prescribes particular imaginings - such as the child is making a phone call -for participants of the game. Representational arts like literature and painting are similar to a toy phone in this crucial respect: they too prescribe particular imaginings for their audiences, whose engagement with them constitute a game of make-believe. In other words, toy phones and paintings alike are props that have the social function of being appreciated via imaginings. As Walton notes, the nature of these imaginings can vary: they can be spontaneous or deliberate, occurrent or non-occurrent, and solitary or social (1990, pp. 13-19).

Walton distinguishes two kinds of worlds that are associated with make-believe games (1990, pp. 57-63). Game worlds are the worlds of 
each imaginer. Work worlds are the worlds prescribed by the prop. Toy phones and paintings come with work worlds, which can be more or less specific, insofar as they prescribe particular imaginings. In using these props in their make-believe games, each imaginer (or each group of joint-imaginers) creates a game world that more or less aims at the work world: they follow the imagination prescriptions to various degrees, and sometimes add details or extensions of their own where the work world lacks specificity. So the child playing with a toy phone can start by pretending to make a call and then imagine a story of its own telling, and similarly the viewer appreciating a painting can start by picturing the scene depicted and imagine a world that goes beyond the surface.

\subsection{Cognition of Nostalgic Foods}

As mentioned before, one motivation for an imaginative account of experiencing nostalgic foods comes straightforwardly from the cognitive science of nostalgia, on which imagination is central to nostalgic episodes in general. However, another motivation for an imaginative account of experiencing nostalgic foods comes from the phenomenology, or subjective character, of experiencing nostalgic foods.

At the start, I talked about the nostalgia evoked by the loo-bah$p \bar{n} g$ from a particular eatery near my home in Taiwan. However, there were two crucial bits of phenomenological detail that are left out from my initial description. First, while my nostalgic episode is specific in some ways, it is general in others. The nostalgia evoked by that loo-bah-p $\bar{n} g$ is about a relatively imprecise time, my childhood, and a relatively imprecise place, my home. Second, given the imprecisions, I am frankly uncertain how true my descriptions are. For all I know, I do not really know how often my parents brought

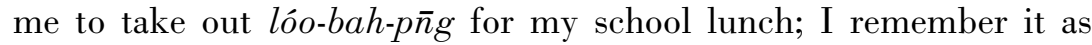
a nearly daily routine, but it could have only happened a couple of times. Importantly, I do not really care about the veracity of my descriptions; even if I were wrong, it would make no difference to my nostalgia. That is, at least phenomenologically speaking, experiencing nostalgic foods seems indifferent to specificity and veridicality.

The imaginative account can explain these puzzling phenomenological features of experiencing nostalgic foods. First, the worlds of our imagination standardly vary in their specificity. We might imagine a very specific castle when we read a fairytale, or we might just be imagining a castle generically. Thinking of food-related nostalgia 
as involving past-directed imaginings means that our representations need not always be about specific events, but instead about something more general - like one's childhood, family, or even something as general as "the way people were". Second, the worlds of our imagination standardly vary in their fidelity to reality. While similarity to reality is a default principle that guides our imaginings, it is also one that can be overridden (Friend 2017). Thinking of food-related nostalgia as involving past-directed imaginings explains why veridicality often seems to be beside the point. Since our experiences of nostalgic foods are standardly centered on past-directed imaginings, it is therefore unsurprising that they have these two subjective characters.

We can now apply Walton's account of make-believe to explicate the experiences of nostalgic foods. Specifically, I will start with experiences of personally-nostalgic foods, in the hopes that they are more readily recognizable, before extending the account to experi-

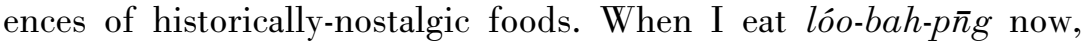
I create a game world about a personally-important experience. As Walton notes, my imaginings might well be spontaneous and nonoccurrent. Some of my imaginings are about specific things, such as

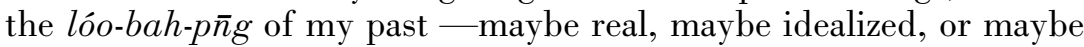
even fictional. ${ }^{4}$ Other imaginings are more like general impressions, such as ones about my childhood and my home. Again, these pastdirected imaginings do not come with the presuppositions of veracity or appropriate causal connections to past experiences.

The same cognitive profile applies to experiences of historicallynostalgic foods. Given that historically-nostalgic foods have the social function of evoking nostalgia, by being appreciated via past-directed imaginings, the game worlds we create do aim at work worlds. We can return to Dunn's anthropological case study to give an example of how imagination works in the cases of culturally-emergent historically-nostalgic foods. When Georgians experienced those homemade canned red tomatoes, they participated in the make-believe of "a lifeworld that was predictable (even if it was predictably awful)" (Dunn 2008, p. 254). Parts of the make-believe might be specific - perhaps moments of consuming food made with industrially canned red tomatoes during the Soviet era- and other parts of the make-believe might be general — such as a sense of "physical safety

${ }^{4}$ For convenience, I am presupposing that we can imagine objectually, such that imaginings can take an object as its content (Noordhof 2002). However, I am ultimately not committed to this ontology of imaginings. For example, my claim here can be recast in terms of events, such as the past events of my smelling, tasting, and

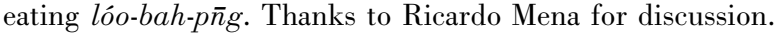


and existential security that no longer obtains" (Dunn 2008, p. 254). Similarly, we can return to Vettel's review of Next's three-cocktails course to give an example of how imagination works in the cases of intentionally-designed historically-nostalgic foods. When Vettel experienced the course, he participated in the make-believe prescribed: a coming-of-age experience of sipping dad's cocktail.

\subsection{Affect and Conation of Nostalgic Foods}

As is the case with nostalgic episodes in general, experiencing nostalgic foods evoke mixed-valenced emotional responses that are, in part, driven by a desire to resolve the incongruence between the subjective past and present. Once again, let us start with experiences of personally-nostalgic foods before extending the account to experiences of historically-nostalgic foods. When I eat ló-bah-pñg now, I have some positive feelings for the imagined past, and some negative feelings about the gap between that imagined past and the actual present. In particular, I am at once directing my emotions at both the loo-bah-png that exists in my past-directed imaginings and the

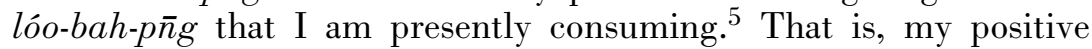
feelings are about the loo-bah-p $\bar{n} g$ in the game world, and my negative feelings are about the differences between those fictive objects and the actual one. Given the incongruence, there is an often unobtainable desire to reconcile the imagined past and the experienced present. As mentioned before, whenever I return to Taiwan, I am motivated by that quixotic desire to go back to the same eatery even though I know that the loo-bah-png. I consume now cannot smell or taste quite like the one that I imagine.

The same affective and conative profile applies to experiences of historically-nostalgic foods. Again, let us return to Dunn's anthropological case study to illustrate the affect and conation of culturallyemergent historically-nostalgic foods. On her analysis, the post-Soviet

\footnotetext{
${ }^{5}$ There is an adjacent philosophical issue on whether there is a fundamental difference between emotional responses to reality and emotional responses to makebelieve. See Friend 2016 for an overview. Walton $(1978,1990,1997)$ famously argued that the latter constitute a distinct kind called "quasi-emotions". This article is only committed to the claim that experiences with nostalgic food standardly include emotional responses to make-believe, and does not take a stance on whether that emotional response is distinctive. Note that, even for the Waltonian, there are quasi-emotions that are directed at non-fictive contents, such as documentaries (Friend 2008). If our emotional responses to nostalgic food turned out to be quasi-emotions, then they would be comparable to our quasi-emotions toward documentaries and other nonfictive contents. Thanks to Hannah Kim and Alessandro Torza for their worries about complications with Walton's quasi-emotions in this context.
} 
Georgians not only desired the smell and taste of Georgian dishes developed during the Soviet era, they also desired the safety and authority of the state: "People's desire for the state, complete with the cohesion of elements that gave it the appearance of unitary authority, was thus made manifest as they tried to replicate the taste of socialism" (Dunn 2008, p. 250). Although she does not explicitly discuss it, one suspects that there is a corresponding affective component as well: a feeling of security toward the past, and a fear of uncertainty toward the present. And again, let us return to Vettel's review to illustrate the affect and conation of intentionally-designed historically-nostalgic foods. He makes the suggestive claim that "Ideally, one would accompany each sip with a furtive, over-the-shoulder glance" (2011). There is a thrill that comes with an illicit comingof-age drink that one can no longer obtain, no matter the technical expertise of the drink maker. And one might seek to experience that imagined past again, even though it is undoubtedly irreconcilable with the actual present.

It is worth emphasizing that, on my account, experiencing nostalgic foods involves emotions that are directed at the imaginary. Scott Alexander Howard makes this same point about what he calls Proustian nostalgia: "As we have seen, in self-aware Proustian nostalgia for the bad, the fictional or aestheticized features of the memory are part of the intentional object of the emotion. But the more that the remembered past diverges from reality, the less the emotion's standards of fittingness might be beholden to the actual past" (2012, p. 648). Indeed, Howard suggests a parallel between the affective aspect of nostalgia and the paradox of fiction, which is usually discussed in the context of representational arts like literature and painting. However, there is a crucial difference between us: while he thinks Proustian nostalgia is only a special case, I think his description of it is generally applicable because imagination is central to all nostalgic episodes-including all experiences of nostalgic foods.

\subsection{Perception of Nostalgic Foods}

In articulating an imaginative account of nostalgic food, I have so far focused on the three psychological components identified by De Brigard's modern conception of nostalgia: cognition, conation, and affect. But a full account of experiencing nostalgic food cannot ignore perception. After all, nostalgic food is something that we smell and taste. So I will articulate three possible — and by no means mu- 
tually exclusive- psychological mechanisms by which imagination can interact with perception. ${ }^{6}$

First, imagination might influence perception directly via cognitive penetration. If cognitive penetration truly occurs (and it is highly debatable whether it does; see Stokes 2013), then the phenomenology and content of our percepts are causally-sensitive to cognitive mental states like imaginings. For example, suppose that cognitive penetration can occur in the experience of nostalgic food. Then, the way that loo-bah-png smells and tastes to me now can differ from the way it would have smelled and tasted to someone without a nostalgia like mine. That is, we would literally smell and taste the same loo-bah$p \bar{n} g$ differently.

Second, imagination might also influence perception indirectly via expectation. As Carolyn Korsmeyer (2002) has articulated, our perceptual experiences with food are often shaped by our expectations. An alcoholic beverage that contains an insect larva might be perceived as delicious if it is taken to be mezcal, but perceived as disgusting if it is not. While these expectations are often the works of beliefs, they can be the works of imaginings too. In the expectation case, unlike in the cognitive penetration case, the respective bare sensations (or lower-level percepts) might remain the same while the overall perceptual experience (or higher-level percepts) significantly differ. This psychological mechanism might be especially suited to explain why nostalgic foods of the present often do not smell or taste the same as their counterparts in the imagined past. For example, as mentioned earlier, the same eatery's loo-bah-p $\bar{n} g$ never tastes quite like the ones I am nostalgic for. Since the eatery has not changed its recipe, the most plausible explanation says that the difference is not to be found in the way that it actually smells and tastes, but in my broader perceptual experience, which is inescapably shaped by my nostalgia.

Third, imagination might blend with perception to create mixed representations. Robert Eamon Briscoe has introduced the notion of make-perceive to refer to hybrid experiences that involves "both a bottom-up, perceptual component and a top-down, imaginative component" (2018, p. 162; see also Briscoe 2008). In these cases, the imaginings are projected onto, or "materially anchored", to the percepts: for example, a sailor might perceive the particular locations of stars above the horizon and imagine the destination as being a particular distance away, beyond the horizon. In experiencing nostalgic food, we might do something similar. For example, when I consume

\footnotetext{
${ }^{6}$ Compare Korsmeyer 2019.
} 
lóo-bah-p $\bar{n} g$ now, I might project my imaginings, desires, and feelings about my childhood and home onto each bite. Quite literally, in the mixed representation case, we can be said to be smelling and tasting the past, via our make-percepts, when we consume nostalgic food.

\section{Aesthetics of Nostalgic Foods}

There is an ongoing debate concerning the artistic status of food (Meskin 2013). Its central question, at least on one way of phrasing it, is whether food is art like literature and painting. I am not convinced that this is the most philosophically productive question to ask, especially given the ongoing debate about the concept of art itself (Liao, Meskin, and Knobe 2020). Instead, I want to turn to a nearby question: whether food can afford aesthetic experiences comparable to ones afforded by literature and painting. ${ }^{7}$ To start, I will review Elizabeth Telfer's argument for answering this question negatively, which also serves as the basis of her position that food is only a minor art (subsection 4.1). Then, I will return to the psychological profile of experiencing nostalgic foods to argue against Telfer (subsection 4.2).

\subsection{Telfer on the Aesthetic Experience of Food}

Telfer argues that food is only a minor art because she wants to temper our expectations regarding the aesthetic experiences that food can afford: "We also need to find a middle way between two unsatisfactory attitudes to the aesthetic dimension of food: we must not be so heedless as to waste a satisfying kind of aesthetic experience, but not so precious as to expect more of it than it can give" (1996, p. 60). She offers three independent reasons for why food cannot afford aesthetic experiences comparable to ones afforded by canonical arts such as literature and painting.

First, food cannot have permanence. Major art must not be transient for two reasons: it has to be around long enough to be contemplated, and it has to have the chance to speak to different gen-

${ }^{7}$ Of course, there is also an ongoing debate about what makes an experience aesthetic (Shelley 2017, sec. 2.4). My original intention is to use the term 'aesthetic experience' in an intuitive and uncommitted sense, but it may turn out that - given the emphasis on psychological mechanisms - my account is friendlier to internalist theories, which locates the aesthetic in the experience itself and not in the object of the experience. It should also be said that with nostalgic (and other) foods, like with literature and painting, there can be a variety of other experiences, such as religious and political. In many cases, these experiences are simultaneous to, and in interaction with, the aesthetic experiences. However, the present exploration of nostalgic food focuses only on the aesthetic aspect. 
erations (1996, p. 58). Since food is not around long enough to be contemplated, let alone around long enough to speak to different generations, it cannot be a major art.

Second, food cannot have meaning. Major art tends to be representational because then it has the capacity to tell us something about the world and about ourselves (1996, p. 59). Some nonrepresentational arts, such as music, can still be meaningful because they manage to express emotions in themselves (Telfer 1996, p. 59). However, according to Telfer, food can — at best - only be a vehicle via which the cook expresses emotions. Since food cannot represent in the same way that fine arts can and cannot express emotion in itself, it cannot be a major art.

Third, food cannot be moving. Major art can evoke significant emotional responses. While food can "elate us, invigorate us, startle us, excite us, cheer us with a kind of warmth and joy, [it] cannot shake us fundamentally in that way of which the symptoms are tears or a sensation almost of fear" (1996, p. 59). Since food cannot evoke significant emotional responses from the consumers, it cannot be a major art.

Although Telfer does not explicitly define her taxonomy of major versus minor arts, her discussion suggests that it has two aspects. Most apparently, Telfer's taxonomy seems to track a distinction in the Western canon between fine arts and other cultural achievements, which are variously called decorative arts, applied arts, or crafts. This distinction between different types of artistic and cultural achievements is itself a product of, and continues to reinforce, a hierarchy of senses in the Western canon, according to which sight and hearing - the senses of fine arts - are thought to be superior to smell, touch, and taste (Korsmeyer 1975). More substantively, Telfer's taxonomy also tracks an alleged distinction between the aesthetic experiences that are afforded by different artistic and cultural achievements. Minor arts can only afford simple aesthetic experiences — without permanence, meaning, or movingness - and so they are, as a kind, aesthetically inferior. Telfer's argument for food as a minor art, then, can be understood as justifying the traditional hierarchy by appeal to the aesthetic experience affordances of different artistic and cultural achievements.

\subsection{Response to Telfer}

While I am skeptical of each of Telfer's three criteria for distinguishing major art from minor art, I will not directly argue against 
them. Instead, my argumentative strategy will be to show that, even if Telfer were right about all three criteria, food can still be a major art. While Telfer does not comprehensively categorize the arts into major versus minor, her discussions suggest that literature and painting are good examples of major art. So, my argumentative strategy will be to show that food can afford aesthetic experiences comparable to ones afforded by literature and painting. On my diagnosis, all of Telfer's reasons for why food is only a minor art depend on the implicit assumption that the aesthetic experiences of food are primarily sensory. ${ }^{8}$ And it is this assumption that I want to challenge. The recognition of imagination's centrality in experiencing food -as shown by the psychological profile of experiencing nostalgic foodsshows that, at its best, food can afford aesthetic experiences relevantly similar to recognized major arts such as literature and painting.

I am certainly not the first to recognize the role of imagination in the aesthetic experience of food. Even though Korsmeyer (1999) seems to share Telfer's view that food is only a minor art - "Culinary art can still be considered a minor or a decorative art, or perhaps a functional or applied art" (p. 144) - she has also argued for imagination's role in the aesthetic experience of food in her monograph on taste. ${ }^{9}$ Korsmeyer writes, "Clearly the imagination plays a big role in what counts as appetizing, not only the olfactory, gustatory, and visual senses" (1999, p. 175; cf. p. 91). Korsmeyer argues that imagination's role is especially recognizable when we consider the practice of food science labs, which seek to - as much as possiblequarantine tasters' imaginings from their senses (1999, p. 91). Aaron Meskin (manuscript) explores imagination's role in the aesthetic experience of food from the case of so-called "mock food", such as imitation meat. I think that nostalgic foods provide yet another case

\footnotetext{
${ }^{8}$ Korsmeyer makes a similar remark in response to Telfer: "Yet food and works of art share significant features that are often overlooked if one focuses only on sensuous taste pleasure" (2002, p. 218). Korsmeyer's diagnosis and mine, while not mutually-exclusive, have different emphases: hers is on symbolic meaning, and mine is on imagination.

${ }^{9}$ This quote, admittedly, does not fully capture Korsmeyer's complicated view on food and art. She does not think that the "art" label is particularly important. Moreover, she worries that the attempt to group all cultural achievements under the "art" label might impoverish our understanding of cultural achievements such as food, given their different cultural roles. For example, the "art" label might make us focus too much on gourmet food rather than ordinary food. In Korsmeyer 1999, she explicitly and critically discusses Telfer's reasons for why food is only a minor art (pp. 108-110). In Korsmeyer 2002, she notes that "Foods and their tastes may represent and express significance in a distinctively 'aesthetic' fashion" (p. 218).
} 
for recognizing imagination's role in the aesthetic experience of food, and it arguably has the advantage of being a more mundane and universal experience.

First, Telfer thinks that food cannot be around long enough to be contemplated because she is focusing on the sensory experience of food. Once you eat it, you can no longer smell it or taste it. That is true, but you can still imagine it. Nostalgic food is anything but transient. Historically-nostalgic foods show that food can be around long enough to speak to different generations. For example, as a Taiwanese person who has not personally experienced the pre-economic-development eras, I can still imagine that past when I eat han-tsî-muê today. The same, one would expect, can be said of Georgians who have not personally experienced the Soviet era when they eat canned red tomatoes today. The power of these culturallyemergent historically-nostalgic foods lies in their ability to exist in the past-directed imaginings across generations such that they become an integral piece of the respective cultural identities. Indeed, the marketing of such historically-nostalgic foods would be wholly unsuccessful if consumers could not have such past-directed imaginings.

Second, Telfer thinks that food cannot be meaningful because rarely can meaning be directly gained from the senses, especially the so-called "lower" senses of smell, touch, and taste. Even if the traditional hierarchy of senses were true, historically-nostalgic foods can still function as props for make-believe, just like literature and painting. And so they can convey meaning through the same psychological mechanism: imaginings. When one reads Vittel's vivid description of his own experience of Next's three-cocktails course, it is difficult to maintain that food, even at its best, still cannot engage imagination to convey meaning in the same way that literature and painting can.

Third, Telfer thinks that food cannot evoke significant emotional responses, at least ones that are directed at fictive objects, because senses alone are often not enough to do so. As many people can attest, however, personally-nostalgic foods can certainly move us in deep ways including tears and fears. But even historically-nostalgic foods can do the same. Consider again Vettel's suggestion that each cocktail sip be accompanied by a furtive, over-the-shoulder glance. That nuanced mix of fear and excitement is not only a fitting response, but central to the aesthetic experience.

So, contrary to Telfer, I say that nostalgic foods can afford aesthetic experiences that have permanence, meaning, and movingness. Of course, this claim does not commit me to say that every nostalgic 
food in fact offers such a significant aesthetic experience. For comparison, even though literature and painting can afford comparably significant aesthetic experiences, that is not to say that every work of those kinds does.

Still, one might worry that the make-believe worlds associated with nostalgic foods - even historically-nostalgic foods - are too minimal to ground aesthetic significance. After all, it is unlikely that every Georgian person experiences canned red tomatoes as Dunn describes, and it is unlikely that every Next patron experiences the three-cocktails course as Vettel describes. In response, it is worth returning to literature and painting as our comparisons. With literature and painting, it is clear that minimal make-believe is no impediment to a work's aesthetic significance. Of course it is possible that Vettel, as a food critic, is offering one esoteric and embellished interpretation of Next's three-cocktails course. But similarly, one need not look too hard to find similarly esoteric and embellished interpretations from literary and visual art critics. In fact, arguably the best works are those that can afford multiple meanings and divergent emotional responses. As such, it is at least a possibility that the multiple meanings and divergent emotional responses that nostalgic foods afford actually adds to its aesthetic significance.

On the imaginative account of experiencing nostalgic foods, aesthetic experiences of food can be as significant as aesthetic experiences of literature and painting, even judged by Telfer's three criteria. Nostalgic foods can stay with us, be meaningful to us, and move us. Indeed, they can do so not only throughout our individual lives, but also through generations and generations of our communities. It is thus no surprise that nostalgic foods play an important role in the construction of personal and cultural identities. What is the secret indispensable ingredient? Imagination. ${ }^{10}$

${ }^{10}$ Thanks to many anonymous referees, Paloma Atencia-Linares, Axel Arturo Barceló Aspeitia, Bennett Barnes, Erin Bradfield, Meilin Chinn, Felipe De Brigard, Grant Bartolomé Dowling, David Friedell, Eduardo García Ramírez, Colleen Hanson, Eric Hochstein, Gregg Horowitz, Hannah Kim, Carolyn Korsmeyer, Samantha Lilly, Ricardo Mena, Aaron Meskin, Harold Parker, Sara Protasi, Michael Rings, Miguel Ángel Sebastián, Robert Shanklin, Thomas Slabon, Matt Strohl, Alessandro Torza, Tung-ying Wu, Michel-Antoine Xhignesse, Eric Yang, Audrey Yap, James O. Young, and everyone at Fagothey Philosophy Conference on Aesthetics, Art, and Life at Santa Clara University, the Conference on Food, Art, and Philosophy at National Autonomous University of Mexico, the Salish Sea Aesthetics Conference at University of British Columbia, and the departmental colloquium at the University of Victoria. 


\section{REFERENCES}

Bak-Geller Corona, Sarah, 2019, "The Cookbook in Mexico: A Founding Document of the Modern Nation", in Atsuko Ichijo, Venetia Johannes, and Ronald Ranta (eds.), The Emergence of National Food: The Dynamics of Food and Nationalism, Bloomsbury Academic, New York, pp. 28-38.

— 2016, "Culinary Myths of the Mexican Nation", in Ishita BanerjeeDube (ed.), Cooking Cultures: Convergent Histories of Food and Feeling, Cambridge University Press, New York, pp. 225-246.

Batcho, K.I., 2013, "Nostalgia: The Bittersweet History of a Psychological Concept", History of Psychology, vol. 16, no. 3, pp. 165-176.

Briscoe, Robert Eamon, 2018, "Superimposed Mental Imagery: On the Uses of Make-Perceive", in Fiona Macpherson and Fabian Dorsch (eds.), Perceptual Imagination and Perceptual Memory, Oxford University Press, New York, pp. 161-185.

, 2008, "Vision, Action, and Make-Perceive", Mind and Language, vol. 23, no. 4, pp. 457-497.

Chang, May Yu-hsin, 2013, "Nostalgic Imagination: A Study of the Sweet Potato in Taiwan", in Sidney C.H. Cheung and H.W. Chau (eds.), Foodways and Heritage: A Perspective of Safeguarding the Intangible Cultural Heritage, Hong Kong Heritage Museum, Hong Kong.

De Brigard, Felipe, 2018, "Nostalgia and Mental Simulation", in Anna Gotlib (ed.), The Moral Psychology of Sadness, Rowman and Littlefield, London, pp. 155-181.

—_ 2017, "Memory and Imagination", in Sven Bernecker and Kourken Michaelian (eds.), The Routledge Handbook of Philosophy of Memory, Routledge, New York, pp. 127-140.

—_, 2014, "The Nature of Memory Traces", Philosophy Compass, vol. 9, no. 6, pp. 402-414.

Debus, Dorothea, 2018, "Memory, Imagination, and Narrative", in Fiona Macpherson and Fabian Dorsch (eds.), Perceptual Imagination and Perceptual Memory, Oxford University Press, New York, pp. 72-95.

—_, 2016, "Imagination and Memory", in Amy Kind (ed.), The Routledge Handbook of Philosophy of Imagination, Routledge, New York, pp. 135-148.

—_ 2014, "Mental Time Travel: Remembering the Past, Imagining the Future, and the Particularity of Events", Review of Philosophy and Psychology, vol. 5, no. 3, pp. 333-350.

Dunn, Elizabeth Cullen, 2008, "Postsocialist Spores: Disease, Bodies, and the State in the Republic of Georgia", American Ethnologist, vol. 35, no. 2, pp. 243-258.

Friend, Stacie, 2017, "The Real Foundation of Fictional Worlds", Australasian Journal of Philosophy, vol. 95, no. 1, pp. 29-42. 
Friend, Stacie, 2016, "Fiction and Emotion", in Amy Kind (ed.), The Routledge Handbook of Philosophy of Imagination, Routledge, New York, pp. 217-229.

__ 2008, "Imagining Fact and Fiction", in Kathleen Stock and Katherine Thomsen-Jones (eds.), New Waves in Aesthetics, Palgrave Macmillan, New York, pp. 150-169.

Gotlib, Anna, 2018, "Memory, Sadness, and Longing", in Anna Gotlib (ed.), The Moral Psychology of Sadness, Rowman and Littlefield, London, pp. 183-205.

Hepper, Erica G., Timothy D. Ritchie, Constantine Sedikides, and Tim Wildschut, 2012, "Odyssey's End: Lay Conceptions of Nostalgia Reflect Its Original Homeric Meaning", Emotion, vol. 12, no. 1, pp. 102-119.

Hepper, Erica G., Tim Wildschut, Constantine Sedikides, Timothy D. Ritchie, Yiu-Fai Yung, Nina Hansen, Georgios Abakoumkin, Gizem Arikan, Sylwia Z. Cisek, Didier B. Demassosso, Jochen E. Gebauer, J.P. Gerber, Roberto González, Takashi Kusumi, Girishwar Misra, Mihaela Rusu, Oisín Ryan, Elena Stephan, Ad J.J. Vingerhoets, and Xinyue Zhou, 2014, "Pancultural Nostalgia: Prototypical Conceptions Across Cultures", Emotion, vol. 14, no. 4, pp. 733-747.

Hopkins, Robert, 2018, "Imagining the Past: On the Nature of Episodic Memory", in Fiona Macpherson and Fabian Dorsch (eds.), Perceptual Imagination and Perceptual Memory, Oxford University Press, New York, pp. 46-71.

Howard, Scott Alexander, 2012, "Nostalgia", Analysis, vol. 72, no. 4, pp. 641-650.

Korsmeyer, Carolyn, 2019, “A Tour of Senses", British Journal of Aesthetics, vol. 59, no. 4, pp. 357-371.

, 2016, The Taste Culture Reader: Experiencing Food and Drink, 2nd ed., Bloomsbury, New York.

— 2002, "Delightful, Delicious, Disgusting", The Journal of Aesthetics and Art Criticism, vol. 60, no. 3, pp. 217-225.

, 1999, Making Sense of Taste, Cornell University Press, Ithaca.

, 1975, 'On the 'Aesthetic Senses' and the Development of Fine Arts", The Journal of Aesthetics and Art Criticism, vol. 34, no. 1, pp. 67-71.

Liao, Shen-yi, Aaron Meskin, and Joshua Knobe, 2020, "Dual Character Art Concepts", Pacific Philosophical Quarterly, vol. 101, no. 1, pp. 102-128. Liao, Shen-yi and Tamar Szabó Gendler, 2019, "Imagination", The Stanford Encyclopedia of Philosophy, downloaded from <https://plato.stanford. edu/entries/imagination/> [accessed: 25/01/2019]

Locher, Julie L., William C. Yoels, Donna Maurer, and Jillian van Ellis, 2015, "Comfort Foods: An Exploratory Journey Into The Social and Emotional Significance of Food", Food and Foodways, vol. 13, no. 4, pp. 273-297. 
Meskin, Aaron, 2013, "The Art of Food", The Philosopher's Magazine, no. 61, pp. 81-86.

(manuscript), "Eating, Drinking, and Imagining".

Michaelian, Kourken, 2018, "Episodic and Semantic Memory and Imagination: the Need for Definitions", American Journal of Psychology, vol. 131, no. 1, pp. 99-103.

of the Personal Past, MIT Press, Cambridge, MA.

Michaelian, Kourken and John Sutton, 2017, "Memory", The Stanford Encyclopedia of Philosophy, downloaded from < https://plato.stanford.edu/ entries/memory/> [accessed: 25/01/2019]

Noordhof, Paul, 2002, "Imagining Objects and Imagining Experiences", Mind and Language, vol. 17, no. 4, pp. 426-455.

Rea, Naomi, 2017, "For Her Latest Feat, Marina Abramović Has Transformed Herself Into a Macaron", ArtnetNews, downloaded from < https:/web. archive.org/web/20190125191122/https://news.artnet.com/art-world/mari na-abramovic-macaron-1102277> [accessed: 25/01/2019]

Robins, Sarah, 2020, "Defending Discontinuism, Naturally", Review of Philosophy and Psychology, vol. 11. no. 2, pp. 469-486.

Schacter, Daniel L., Donna Rose Addis, and Randy L. Buckner, 2007, "Remembering the Past to Imagine the Future: the Prospective Brain", Nature Reviews Neuroscience, vol. 8, no. 9, pp. 657-661.

Sedikides, Constantine and Tim Wildschut, 2016, "Nostalgia: A Bittersweet Emotion that Confers Psychological Health Benefits", in Alex M. Wood and Judith Johnson (eds.), The Wiley Handbook of Positive Clinical Psychology, Hoboken, Wiley, NJ, pp. 25-136.

Shanton, Karen and Alvin Goldman, 2010, "Simulation Theory", Wiley Interdisciplinary Reviews: Cognitive Science, vol. 1, no. 4, pp. 527-538.

Shelley, James, 2017, "The Concept of the Aesthetic", The Stanford Encyclopedia of Philosophy, downloaded from < https://plato.stanford.edu/ entries/aesthetic-concept/> [accessed: 25/01/2019]

Stern, Barbara B., 1992, "Historical and Personal Nostalgia in Advertising Text: The Fin de siècle Effect", Journal of Advertising, vol. 21, no. 4, pp. 11-22.

Stokes, Dustin, 2013, "Cognitive Penetrability of Perception", Philosophy Compass, vol. 8, no. 7, pp. 646-663.

Strohl, Matthew, 2019, "On Culinary Authenticity", The Journal of Aesthetics and Art Criticism, vol. 77, no. 2, pp. 157-167.

Telfer, Elizabeth, 1996, Food for Thought: Philosophy and Food, Routledge, New York.

Vettel, Phil, 2011, "Next Review: Childhood Menu Re-creates Aromas, Sights, Tastes of Youth", Chicago Tribune, downloaded from < https:// web.archive.org/web/20190125191246/https://www.chicagotribune.com/ dining/restaurants/ct-review-next-childhood-20160128-column.html $>$ [accessed: 25/01/2019] 
Walton, Kendall L., 1997, "Spelunking, Simulation, and Slime: On Being Moved by Fiction", in Mette Hjort and Sue Laver (eds.), Emotion and the Arts, Oxford University, New York, pp. 37-49.

_- 1993, "Metaphor and Prop-Oriented Make-Believe", European Journal of Philosophy, vol. 1, no. 1, pp. 39-57.

- 1990 , Mimesis as Make-Believe, Harvard University Press, Cambridge, MA.

—_, 1978, "Fearing Fictions", The Journal of Philosophy, vol. 75, no. 1, pp. 5-27.

Received: December 17, 2019; revised: May 6, 2020; accepted: July 12, 2020. 